\title{
Contexts, networks, and voting behavior: the social flow of political communication in Italy
}

\author{
MORENO MANCOSU* \\ Collegio Carlo Alberto, Via Real Collegio, Moncalieri, Italy
}

\begin{abstract}
Previous research demonstrated that different contextual sources can affect voting behavior. Homogeneous familiar networks affect individual behavior of people embedded in these networks toward voting for certain parties. Moreover, being exposed to higher levels of homogeneity in the geographical place where one lives contributes to developing higher propensities to vote for a certain political object. By means of 2006 National Italian Elections data (and by employing new measures of network political homogeneity), this paper tests, with multilevel models, the hypothesis according to which networks and geographical context interact while affecting individuals' voting behavior. Results confirm such a hypothesis, showing that familiar networks represent a 'social bubble', which limits the likelihood of being affected by the broader context.
\end{abstract}

Keywords: voting behavior; group dynamics; political culture; Italy

\section{Introduction}

The relationship between voting and social, geographical, or institutional context has occupied a major role in the study of electoral behavior (Marsh, 2002). This is especially true in Italy, where the relationship between voting behavior and subnational political culture was one of the prominent topics of Italian electoral studies (e.g. Galli, 1968; Diamanti, 2003). Several studies attempted to disentangle the connection between the vote and sub-cultural legacies by arguing the intimate relationship between geographical/spatial context, social context, and political attitudes (see Sani, 1976). The debate around voting behavior and different contextual levels has risen at the end of the eighties, owing to the work of Huckfeldt and colleagues (Huckfeldt, 1986; Huckfeldt and Sprague, 1987; Baybeck and Huckfeldt, 2002) and mainly by means of American data. However, since the mid-2000s, it seems that interest toward the combined effects of geography and networks has declined. Consequently, electoral geographers lost interest in the relational mechanisms leading to empirical regularities they analyze at the aggregate levels and political network analysts seem to have disregarded that broader environments actually contribute to shaping individual voting behaviors. This study aims to take up

* E-mail: moreno.mancosu@carloalberto.org 
the thread by combining the effects of a broader context and networks in the explanation of voting behavior, testing the fundamental expectations concerning this topic in the literature, by means of 2006 Italian National Elections data.

According to the 'social logic of politics' (Zuckerman, 2005), voting is, among other things, a social activity; discussion networks represent the environment wherein people structure their attitudes and political preferences (Berelson et al., 1954; Huckfeldt and Sprague, 1995; Huckfeldt et al., 2004; Zuckerman, 2005). Discussions with other citizens can crystallize, slightly change, or even throw into crisis one's ideas, beliefs, and opinions.

However, discussions with friends and relatives are not the sole source of political information and influence in a contemporary democracy. By shaping the structural context of individual opportunities of encountering a supporter of a certain party, the general climate or the local environment crucially contributes to affect individuals' voting behaviors and political opinions. According to this latter framework, the 'general climate' concept is strictly related with 'geographical context' or 'place' concepts (e.g. Agnew, 1987, 1996). Place is designed as one of the main analytical environments wherein electoral behavior is constructed and choices are crystallized. This is particularly true in Italy, a country characterized by a largely studied geographical stability of political preferences, usually known as electoral geopolitics; namely, a strong, time-invariant geographical stability of different parties' electoral spheres of influence (Galli, 1968; Diamanti, 2003).

The geographical context, however, does not affect in the same way every individual. For instance, it has been stressed elsewhere (Huckfeldt and Sprague, 1987; Erisen and Erisen, 2012) that more intimate relationships act as a filter with respect to broader social context; networks, especially when they are close-knit, constitute a 'social bubble' that limits communication (and influences processes) with the broader context. This expectation will be tested in this study, by means of 2006 National Elections Italian National Election Studies (ITANES) data.

With respect to the majority of previous works that treat the relationship between geographical context and networks, this work presents at least two elements of innovation. The first concerns the national context wherein hypotheses will be tested. As pointed out in different works (Hopmann, 2012; Eveland et al., 2015), the large portion of empirical evidence concerning the relationship with individual vote choices and networks is of American origin. If we except a small number of contributions (Campus et al., 2008; Baldassarri, 2009; Guidetti et al., 2016; Vezzoni and Mancosu, 2016), the attempt to test network-based hypotheses in Italy is quite small, while works that identify both geographical context and networks as relevant predictors of political choice are just occasional (Sani, 1976); this gap in the literature is even more serious if we consider that Italy presents an ideal situation of testing such hypotheses because of the geographical scattering of its political landscape.

In addition to the object of our inquiry, the work presents some differences from what regards the operationalization of the variable. A large portion of works 
dealing with network effects is based on network data collected by means of the socalled name generator batteries. Respondents are asked to cite one or more (usually up to five) discussants and some of their properties in order to enable the researcher to identify the nature of respondent's ego network. The operational strategy of this study will follow a slightly different path. Consistently with the measure proposed by Baldassarri (2009), in 2006 ITANES data, it has been asked the respondent to provide a percentage of how many people of the relatives circle were supposed to support one coalition or another. In that way, we have the opportunity to evaluate general preferences of an entire social circle instead of a small number of individuals.

Results of the analyses are consistent with theoretical expectations: people seem to be actually affected by both the network and geographical homogeneity. In addition, there is empirical evidence showing that in the presence of homogeneity of cohesive circles, the effect of geographical context is small and non-significant. This is consistent with the idea of strong ties circles (namely, circles in which intimate relationships are numerically relevant) as a 'social bubble' that contributes to detach individuals from being affected by the broader context (such as the geographical one).

\section{Family networks: cohesiveness and homogeneity}

Several arguments can be stressed in the conceptual structure of theorists who underline social context as a predictor of vote choices. First of all, electoral behavior is highly dependent on the social environment in which voters are embedded. Huge stress is given to the role of 'molecular interactions', as well as 'hot communication' inside groups (Baker et al., 2006).

A fundamental characteristic of a political network is its homogeneity. People belonging to highly homogeneous networks are swung toward the party, candidate, or coalition that is supported by the great majority of the network (Berelson et al., 1954). This outcome is hypothesized to be related to a probabilistic mechanism in which being exposed to a lower variety of ideas leads to a decrease of the sources of disagreement and to conform more likely to the dominant opinion (Latané, 1996; Huckfeldt et al., 2004; Rolfe, 2009). As Huckfeldt et al. point out, '[i]f you are a liberal Democrat, and all your friends are liberal Democrats, the odds are very high that you will never hear one of your friends make a passionately convincing argument in favor of tax cuts. Conversely, if you are a conservative Republican, and all your friends are conservative Republicans, the odds are similarly high that you will never hear a friend make a passionately convincing case for eliminating restrictions on abortion' (2004). Otherwise, when political networks are heterogeneous, communications can lead to ambivalent reactions about candidates and parties.

The second, crucial characteristic of a network is its cohesiveness. According to the theory of Granovetter $(1973,1983)$, the distinction between weak and strong ties is crucial in understanding the pattern of communication networks. From one 
side, a pattern of strong ties is characterized by an environment in which everyone knows each other. Consequently, ideas and attitudes remain stably enclosed in that network. Conversely, dealing with weak ties means an exposure to less cohesive patterns of communication, which can lead to being exposed to different ideas and new experiences (Vezzoni and Mancosu, 2016). However, the very concept of 'weak ties' assumes that these discussants are often relatively unimportant with respect to strong ties. Huckfeldt et al. (1995) simplify the pattern of weak and strong relationships by distinguishing a network between cohesive social groups (i.e. groups characterized by a high prevalence of strong ties) and circles lying outside this closed group, also called non-cohesive social groups, such as friends, neighborhoods, and co-workers (Huckfeldt et al., 1995). Huckfeldt et al. define the family as the most ubiquitous cohesive social circle.

People who belong to cohesive social circles are more intimate and, consequently, more coerced in their political decision by the rest of the circle. Groups that lie beyond the boundaries of these cohesive circles (friends, acquaintances, co-workers), on the contrary, do not have the same level of coercion (and homogeneity) that the family has.

It has been shown in several works, thus, that family, intended as the closest social circle for an individual, represents the most important group in which voters are embedded (Huckfeldt et al., 1995; Erisen and Erisen, 2012). Family is indeed the first environment in which individuals are politically socialized (Berelson et al., 1954; Stoker and Jennings in Zuckerman, 2005; Zuckerman et al., 2007) and where social ties are 'naturally' strong.

\section{The geographical context}

We can think about local geographical context as a context that encompasses various, more or less homogeneous, networks. Practically, it is possible to intend the role of the geographical place as the simple prevalence of a party in a certain place or by putting it in probabilistic terms, the likelihood of finding a supporter of party $A$ by randomly picking an inhabitant of place $x$. However, according to different works, this view is a rather narrow meaning with respect to the potential of the concept (Agnew, 1987, 1996).

According to electoral geographers' theories, parties, far from being simple collectors of preferences, represent a fundamental intermediate body between civil society and the state. In this respect, we can define their local role as that of a 'channeling resource from center to periphery, [...] rewarding some social and territorial interests at the expense of others' (Shin and Agnew, 2002). Thus, a party is an organization that controls part of the economic flow of resources coming from the center and accounts for redistribution when in charge locally.

Second, support for a certain party can carry a certain set of broader symbolic, interest, and strategic repertoires shared by a part of the population. In other words, 
a place that supports party $A$ does not only represent a probabilistic measure of generic support but also an institutional and cultural factor.

This argument is even more important if we consider the Italian situation, which is characterized by a clear geographical structure. The so-called electoral geopolitics was one of the first tenets of Italian electoral studies (Galli, 1968). Since the postwar period, and consistently all over the so-called First Republic (thus, until 1992-94), Italian territory was fractured into four macro-regions, wherein one of the two main parties (namely, the Christian Democrats and the Communist Party) was dominant. In the northwestern part of the country, Socialist and Communist parties were slightly dominant, while the eastern part of the country was dominated by the Christian Democrats. The central part of the country was definitely dominated by the Communist party, while in the south no strong dominance was present (Galli, 1968; Trigilia, 1981). It is important to notice that these high-level fractures should not be interpreted deterministically; rather, they help to depict a general interpretation of the phenomenon: a more detailed analysis shows how different places can be interpreted as enclaves supporting opponent parties with respect to surrounding zones (Shin and Agnew, 2002). Since the early nineties and with the crisis of the Italian party system, political scientists faced a completely new scenario. The Communist Party collapsed and gave birth to the Partito Della Sinistra (PDS) and a small, more extreme party [Partito della Rifondazione Comunista (PRC)]. From the right side of the political spectrum, the disappearance of the Christian Democrats left a vacuum occupied by the alliance between Berlusconi's Forza Italia, the post-fascist party Alleanza Nazionale and in the Northern part of the country, a regionalist party, the Lega Nord (the Northern League). The revolution occurred in the early nineties along the party landscape and has been widely investigated with sophisticated geographical analyzes (Shin and Agnew, 2002). Results of this political transitions are geographically differentiated: it seems that the transition between the Communist Party and the new alliance between PDS and PRC has been less traumatic with respect to the transition from the Christian Democrats to the alliance between Forza Italia, Alleanza Nazionale, and Lega Nord; similar to many Italian political scientists (Diamanti, 1993; Diamanti, 2003; Floridia in De Sio, 2011), Shin and Agnew (2002) attribute this fragmentation of the transition to a fracture carried by the new parties' characters in zones dominated previously by the Christian Democrats. More precisely, the northeastern part of Italy experienced a revolution in terms of main issues, aims, and identification of its dominant parties: if during the First Republic, the Christian Democrats' ideological basis was characterized by a religious identification, the Second Republic right-wing parties carried a mix of liberal/populist/territorial values that were partly inconsistent with the previous frame. Conversely, the transition in places where the former PCI (Partito Comunista Italiano) was dominant has been less traumatic because of the political continuity between the old party and the new center-left spectrum: 'While the Northern League clearly exhibits [...] a territorial re-framing in the Veneto, the PDS and RC continue to benefit from the territorial and political legacies of the PCI in Tuscany' (Shin and Agnew, 2002). 
If possible, this geographical scattering was even more pronounced and clear during the National elections of 2006. The structure of the competition and the electoral law ${ }^{1}$ indeed favored the emergence of two big political cartels: from the left side of the political spectrum, the Unione (the Union), a coalition united under the figure of the ex-EU commissioner Romano Prodi, represented probably one of the most heterogeneous coalitions in Italian history, collecting both left-wing postChristian Democrats parties and post-communist formations. The other side of the political spectrum, stably controlled by Silvio Berlusconi and his Forza Italia, collected the support of the post-fascist Alleanza Nazionale and the ethno-regionalist party, the Lega Nord, plus a galaxy of small or irrelevant parties (the coalition continued, as in the 2001 elections, to be named 'Casa delle Libertà', the Freedom House). As a result of the crystallization of two ideologically opposite poles, the support for third forces declined sharply: '[i]f in 2001 support for these forces was $4 \%$ (and climbs to over 10\% if one includes forces [...] aligned in 2006 but which in 2001 competed against the two coalitions) then in 2006 it was barely $1 \%$, (Newell, 2006).

The second, and more interesting to our aims, political result concerns the outcomes of the electoral consultation: the 2006 election, indeed, was one of the 'closest fought' in Italian history, in which Romano Prodi's Unione won by $<25,000$ votes of difference in the Chamber of Deputies with respect to the Casa delle Libertà. In the Senate, the Unione won only two seats more than its opponent, leading thus to a fragile government. Such a close competition stresses the differences between different parts of the country. Figure 1 presents the geographical distribution of the plain difference (center-right minus center-left) between coalitions.

As we can see, the situation is very similar to the one described by Italian political scientists since the sixties. A northeastern part is dominated by right-wing parties, a central part of the country strongly dominated by left-wing parties, and a south in which the pattern is not clear.

\section{Integrating different contexts and networks}

It has been argued, separately and for different reasons, that both network exposure and geographical context should exert an effect on political views. More precisely, we can argue that as long as homogeneity toward a certain party/coalition, in networks and local context, rises, people embedded in these contextual levels will have higher likelihoods of voting for that party/coalition.

\footnotetext{
1 The electoral law voted in 2005 sees a high threshold for parties who are not in a coalition that goes beyond $10 \%$ in the Chamber of Deputies. In this case, a 'non-aligned' parties' threshold would have been $4 \%$. On the contrary, it would be easier for these parties to enter in parliament if in a coalition (the threshold is $2 \%$ ). This aspect of the electoral law produced the centripetal force that made the two main coalitions catch almost the total share of voters in 2006.
} 


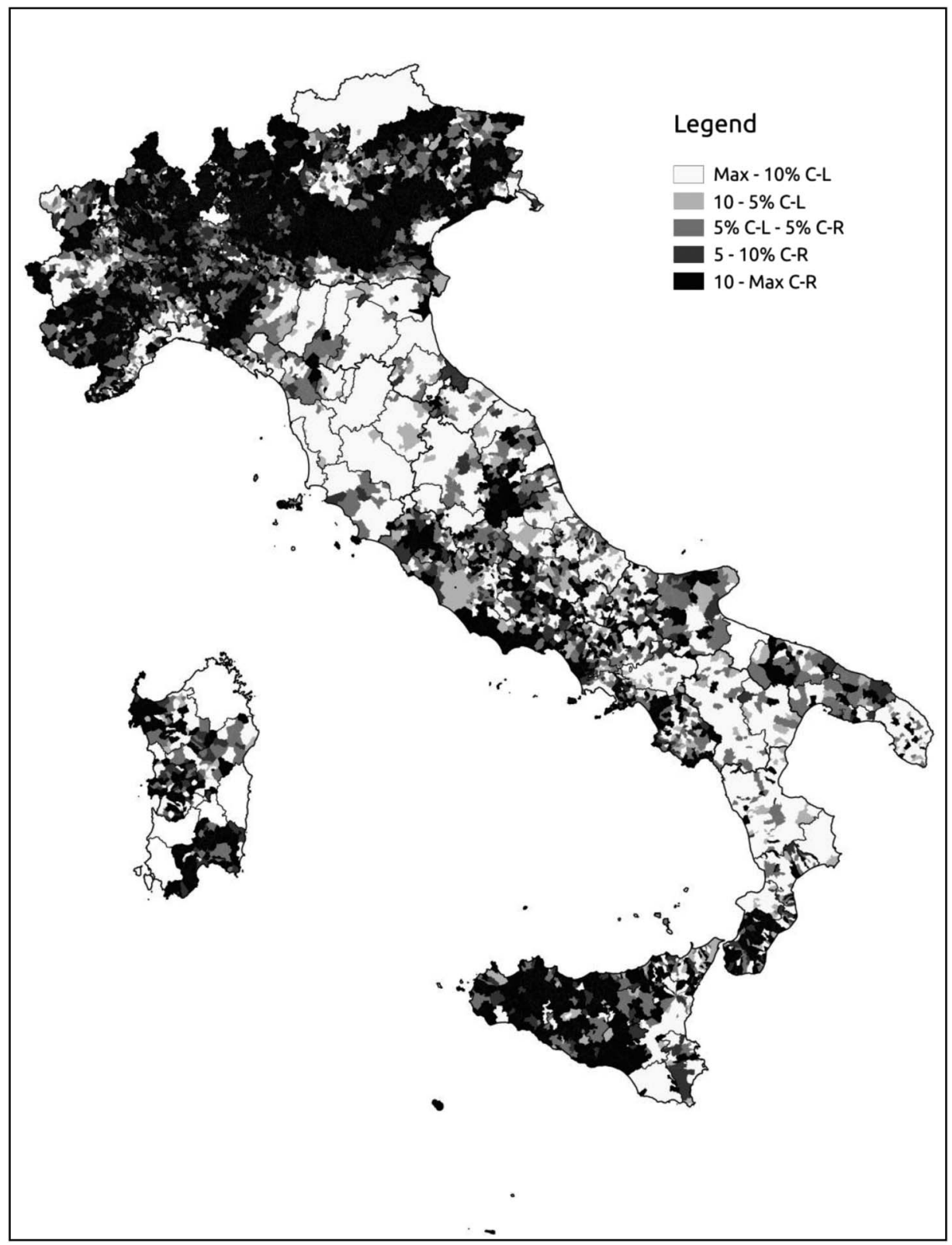

Figure 1 The competition of center-left and center-right coalitions in the 2006 elections: differences in percentage points between the two coalitions. Brightest municipalities are those in which the center-left dominates with a larger difference of percentage points over center-right. The same holds for center-right in darkest municipalities. 
However, other studies have stressed that the two analytical levels can interact among them (Huckfeldt and Sprague, 1987; Erisen and Erisen, 2012). It has been stressed, especially with regard to family circle, that homogeneous networks can represent some social filter of the broader context. In particular, the family represents an environment wherein external stimuli (coming, for instance, from the geographical environment in which the network is placed) are blocked or altered. This can be sustained for two reasons.

First, people exposed to cohesive social groups tend to be more coerced in their attitudes and behaviors with respect to other groups. As pointed out by Huckfeldt and Sprague (1995), discussing, interacting, and arguing with people of our network lead us to be exposed to different arguments coming from different sources, with which we share different degrees of intimacy, time spent together, and emotional and material exchanges. We can thus legitimately argue that the more the sources of information we interact with are intimate with us, the more their opinion will be taken into consideration and less likely other sources of political information (weak ties, or environmental stimuli) will be taken in consideration. This expectation has been demonstrated by several works (Huckfeldt and Sprague, 1995; Mutz, 2002; Huckfeldt et al., 2004), which show how strong relationships tend to present higher levels of opinions' homogeneity.

The second reason is related to the very network structure of a cohesive social group. As Huckfeldt et al. states, political information communicated through strong ties is forced to travel not so far because it is more likely to feed back to the point of origin. According to Granovetter's (1973) theory, if $A$ has a strong relationship with $B$ and $B$ has a strong relationship with $C$, there is a high probability that $C$ is in relationship with $A$. That means that certain information is looped across these individuals. Thus, a strong-tied circle 'protects' its members from external political sources of information. Consequently, people embedded in these networks are less prone to be affected by external factors and are more prone to maintain previous behaviors.

If we accept this framework, it is possible to logically derive that homogeneity of the network is crucial in identifying the tradeoff between different contextual effects. Ceteris paribus, a highly politically homogeneous network environment is more efficient in blocking, or filtering, external sources of political information, compared with a social network with low levels of political homogeneity. We can thus argue the importance of a homogeneous and cohesive network in shaping the extent to which an individual is affected by the strength of a party/coalition in the geographical space. The second hypothesis will thus read as follows: as long as an individual is exposed to a homogeneous cohesive social group, the effect of the geographical place will be lower. ${ }^{2}$

\footnotetext{
2 The theoretical framework exposed so far can be labeled as an assimilationist one, especially for what concerns network effects. It is indirectly stated, indeed, that an individual exposed to different contextual levels has no power in choosing his/her discussants. As a result, influence processes are the only ones to be
} 


\section{Data, variables, and methods}

\section{Data and variables}

The ITANES (2006) data set is a two-wave pre-post election panel. The pre-election wave was conducted between 1 and 2 months before the elections and sampled 2005 cases, while post-electoral interviews were collected about a month after the elections, and counted 1403 cases (about $70 \%$ of the original sample). Relevant variables for this work were collected in the second wave of the panel, while controls (such as age, gender, educational level, and so on) were collected in the preelection wave. Particularly interesting for our aims is the sampling strategy of this data. A multistage sampling has been adopted, that is, at a first stage, 161 municipalities have been randomly selected among the 8103 municipalities in Italy. At a second stage, a number of individuals, not less than six per municipality, have been randomly sampled in every selected municipality. This structure of the data does its best when analyzed with multilevel techniques (see Snijders and Bosker, 1999; Gelman and Hill, 2006).

Our purpose is to model voter's perceived viability of different coalitions as an electoral option, given their exposure to cohesive social groups and the contextual set of opportunities. A promising candidate to become the dependent variable is the propensity to vote (henceforth PTV) for the main parties that ran in the 2006 Italian National Elections (Tillie, 1995; van der Eijk and Franklin, 1996; van der Eijk et al., 2006). ITANES (2006) presents the classical formulation of the question: respondents are asked to indicate, on an 11-point scale, how likely it is that they will ever vote for several parties and for the two coalitions that ran in the 2006 elections, l'Unione and la Casa delle Libertà. ${ }^{3}$

As van der Eijk et al. (2006) point out PTVs are a non-ipsative measure; this means that a high PTV for party $A$ does not necessarily lead to low values of PTV for parties $B, C$, or $D$. Psychological processes implying PTV measures differ from those related to vote choice, in which having voted for a party automatically implies that all the other parties have not been chosen by the respondent. Research showed that the party which receives the highest PTV is the most likely to be chosen in the actual vote choice; however, it has been simultaneously demonstrated that 'in all member states of the EU there are a substantial number of voters whose preference for the second most preferred party lag only minimally behind their preference for the most preferred one' (van der Brug et al., 2007). In this case, a slight difference at the level of national constraints (for instance, at the level of party competition), can

theorized here and no selection/unfriending situation is expected (Noel and Nyhan, 2011; Bello and Rolfe, 2014). This issue will be further deepened both in the Methods and Conclusion sections.

${ }^{3}$ More precisely, the wording of the question reads as follows: 'We have a number of parties in Italy each of which would like to get your vote. A part from which party did you voted in previous elections, how probable is it that you will ever vote for the following parties? Could you please indicate your opinion on a scale from 0 to 10 , where 0 means 'not at all probable' and 10 'Very probable'?'. 
change the rank order of the preferred party for that individual, leading eventually to a different vote choice.

Much literature has employed PTVs for comparative (namely, cross-national) analysis. In this work, however, the investigation of PTVs in a single national context allows us to study the attitudes toward coalitions people have not voted for, something that would be impossible with the employment of binary vote intention or with vote recall variables. PTVs, indeed, supply a sort of observed utility. Thus, in our analysis, the PTVs for the two different coalitions represent a measure of the viability of these latter as an electoral choice. Broadly speaking, PTVs can be seen as an overall synthetic judgment of the coalitions as political objects that can possess, to voters' eyes, characteristics that make them a more (or less) attractive political options.

One of the two main predictors of the analysis is the perceived support that respondent's social network guaranteed to center-left and center-right coalitions. In other words, respondents have been asked to calculate the percentage of people in their surroundings who support la Casa delle Libertà or l'Unione.

The most straightforward method in the literature to operationalize network characteristics has been asking information about a number (usually up to five) of discussant the respondent is engaged in relationship with. The so-called 'name generator' procedures (Huckfeldt et al., 1995; Huckfeldt et al., 2000; Klofstad et al., 2009) have been crucial for discovering relations between networks and have proven to be reliable and powerful procedures. However, as Baldassarri (2009) notes, name generator procedures - focusing on a few individuals who represent a sort of 'inner circle' of political discussion networks systematically disregard political views and attitudes of the broader social network, that is usually composed of more than three or five discussants. As explained above, what are we looking for here is a measure of homogeneity in a social circle instead of that in a number of discussants. When facing such an issue, name generator procedures become more problematic: by means of name generators, for instance, we do not have a clear idea of the entire social network to which the individual is exposed (Huckfeldt et al., 1995; Baldassarri, 2009; Guidetti et al., 2016).

First, it has been asked to provide some raw measure of the awareness of political opinion of people in the network. The question reads as follows:

1. Think of the members of your family. Would you say that you know the political views of:

None of them $(0 \%)$

A few of them (around 10\%)

Some of them (around 25\%)

About half of them (around 50\%)

Many of them (around 75\%)

Most of them (around 90\%)

All of them (100\%) 
Additionally, two other questions asked directly homogeneity of repondents' network. The two items read as follows:

2. A How many of the members of your family voted for the Casa delle Libertà in the last None of them $(0 \%)$

A few of them [...]

2. B And how many of them voted for the Unione?

None of them $(0 \%)$

A few of them [...]

By means of these questions, we have information about the percentage of relatives our respondent knows the opinion and political homogeneity of these people. Thus, in order to construct our variable, it seems reasonable to have a measure that considers both these pieces of information, that is, a measure that accounts for the share of relatives who could really affect our respondent. The measure that is proposed in this study is calculated as follows: considering the two percentages (homogeneity and awareness) ranging from 1 to 100, the actual homogeneity will be calculated as:

$$
\text { Act_homogeneity } y_{\mathrm{coalx}}=\text { homogeneity } \mathrm{yoalx}_{\mathrm{x}} \times(\text { awareness / 100). }
$$

Where homogeneity coalx is the relative homogeneity for the Unione and the Casa della Libertà, while awareness is divided by 100 and multiplied by the former. Imagine a case of a person who knows the political opinions of $50 \%$ of his/her relatives and knows that $25 \%$ of these people supports, say, the Unione. The individual will be actually exposed to $25 \times 0.5=12.5 \%$ of his/her relatives supporting the Unione. ${ }^{4}$

The other substantively important measure for the work is the political homogeneity at the municipality level: data are collected from the official outcomes by the Minister of Interior. Figure 1 already presented the local distribution of the two coalitions in the country. ${ }^{5}$ The two variables that will be inserted in the model represent the strength of the two coalitions at the municipal level.

\section{Models}

Four multilevel random intercept models will be fitted to test our expectations. Multilevel modeling, in this case, helps us in correcting standard errors that could be

\footnotetext{
${ }^{4}$ It is important to stress that, consistently within our theoretical framework, only the familiar circle will be taken into account in the models. In order to control for other circles, it would be theoretically possible to control for friends and co-workers circles, given that questions about these circles' homogeneity have been asked in ITANES (2006). Unfortunately, these additional controls present many missing values and would erase about $40 \%$ of the sample, leading to unstable estimates. The topic is further developed in the Conclusion and Discussion paragraph.

${ }^{5}$ Center-left coalition parties are those that supported in the 2006 elections for the Chamber of deputies Romano Prodi (L’Ulivo, Rifondazione Comunista, La Rosa nel Pugno, Comunisti Italiani, Italia dei Valori, Federazione dei Verdi, UDEUR, and another six small parties that did not reach the $1 \%$ of valid votes); for the center-right coalition parties, those that supported Silvio Berlusconi as premier (Forza Italia, Alleanza Nazionale, UDC, Lega Nord, and other eight parties that did not reach the $1 \%$ ).
} 
biased by the fact that a crucial measure of our model is collected on another level of analysis (Snijders and Bosker, 1999). The strength of the parties at the local level, indeed, is collected at the municipal level.

The first two models are fitted as follows:

$$
\begin{aligned}
& \text { ptv_cdl = munic_str_cdl+act_homog_cdl+controls } \\
& \text { ptv_uni=munic_str_uni + act_homog_uni+controls }
\end{aligned}
$$

Where ptv_cdl and ptv_uni are the propensities to vote for the two coalitions (the Unione and the Casa delle Libertà), munic_str_cal and munic_str_uni the percentages of the strength of the two parties at the municipal level, act homog_cdl and act_homog_uni the actual (namely, adjusted by the awareness) homogeneity rates of relative circles reported by the respondent.

controls represents a set of variables that are usually employed to predict the vote for center-right or left parties in Italy (see ITANES, 2006; Vezzoni, 2008). Age, gender, educational level (subdivided into 'Elementary school', 'Middle school', 'High school', and 'University degree'), interest in politics (a four-point scale from 'Not interested at all' to 'Very interested'), Employment status (subdivided into 'Not employed', 'private company employee', 'public company employee', 'Autonomous', and 'Atypical'), and a set of dummies indicating the geo-political zone ('North-west', 'North-east', 'Red Belt', 'Center', and 'South and islands'). ${ }^{6}$

These two models are aimed at testing the first hypothesis, concerning the plain and simple effect of the two contextual levels. We have thus hypothesized that both the municipal and the network homogeneity levels influence voting behavior (namely, PTVs for the Unione and the Casa delle Libertà). The second set of regression models considers the second hypothesis about the tradeoff between different contextual levels.

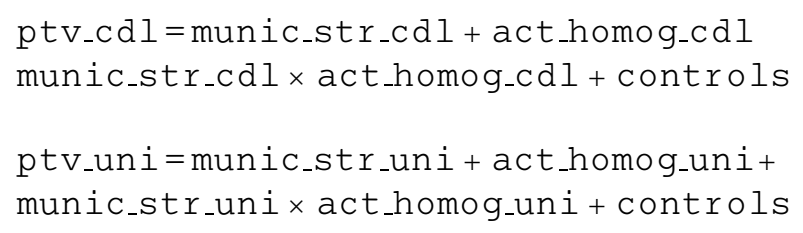

The difference between models 1,2 and 3, 4 is basically the estimation of an interaction between the two contextual variables. If it is true that families act as a social filter with respect to the local environment, relatives' homogeneity must impede the effect of geographical homogeneity. If the hypothesis holds, we should expect negative and significant interaction terms.

\footnotetext{
${ }^{6}$ Descriptive statistics for outcome, substantially relevant variables, and controls are exposed in Appendix 1.
} 
For the sake of our argument, it must be stressed that by means of these regression models, we do not systematically test any effect of influence (as defined by, for instance, Bello and Rolfe, 2014 or Klofstad, 2007). Cross-sectional data are indeed insufficient to test systematically whether our relation is produced by homophily or influence processes (Mollenhorst et al., 2008; Fowler et al., 2011; Lomi et al., 2011). Consequently, nothing forbids us to theorize that people who are more prone to vote for a certain coalition actively decide to be surrounded by homogeneous relations. This would impinge our theoretical results, although it is known that different studies have stressed the relative importance of influence processes in spite of selection procedures (see Bello and Rolfe, 2014). Thus, what we can assess is only that the correlation between homogeneity of different contextual levels and PTV for a coalition is a consistent outcome with our theoretical framework.

\section{Results}

In Table 1 are shown results for the four models presented. Age, gender, and educational level do not seem to have a strong effect on the two dependent variables. Only for people with a university degree is the PTV for the Casa delle Libertà significantly lower (almost one point in both model 1 and 3) with respect to the reference category (elementary degree). Similarly, and consistently with previous result, respondents who are very much interested in politics have lower propensities to vote for the center-right coalition. Both these results are explainable with the profile of the average supporter of center-right coalitions in Italy, which is usually less politically sophisticated (e.g. Barisione, 2001). The second relevant cleavage that we can see from the analysis of controls in Table 1 is the vastly studied support of autonomous workers for the center-right coalition (see Ballarino et al., 2009). As it is possible to see from Table 1, indeed, autonomous respondents' PTVs for the Casa delle Libertà are significantly higher with respect to other categories and significantly lower when the dependent variable is the PTV for the Unione. This is consistent with a vast literature stressing that autonomous workers tend to vote for center-right parties. Much more problematic is the significant, negative effect that atypical workers have on the PTV for the Unione. However, it must be stressed that this effect is estimated on just 27 cases, and thus it is possible that its substantive meaning is blurred by the scarce number of cases.

The first set of hypotheses states that PTVs for coalitions should be affected by the homogeneity of coalitions themselves in both network and geographical environment. The hypothesis is tested in models 1 and 2 for each of the two coalitions. As it is possible to see from Table 1, both the models present positive and significant values for relative network and local homogeneity. In other words, homogeneity of the coalitions (respectively, the Casa delle Libertà and the Unione) in the familiar network and in the local context enhance the PTV for that coalition. The magnitude of the effects is similar for both the models and contexts. For every point of 
Table 1. Four multilevel regressions for the study of coalitions' propensity to vote (PTV)

\begin{tabular}{|c|c|c|c|c|}
\hline & Model 1 & Model 2 & Model 3 & Model 4 \\
\hline Dependent variables & $\begin{array}{l}\text { PTV Casa delle } \\
\text { Libertà }\end{array}$ & PTV Unione & $\begin{array}{l}\text { PTV Casa delle } \\
\text { Libertà }\end{array}$ & PTV Unione \\
\hline Age & $0.01(0.01)$ & $-0.01(0.01)$ & $0.01(0.01)$ & $-0.01(0.01)$ \\
\hline Gender (ref. male) & $-0.10(0.22)$ & $-0.03(0.21)$ & $-0.12(0.22)$ & $-0.04(0.21)$ \\
\hline \multicolumn{5}{|l|}{ Educational level (ref. Elementary) } \\
\hline Middle school & $-0.15(0.37)$ & $0.01(0.36)$ & $-0.19(0.37)$ & $0.03(0.36)$ \\
\hline High school & $0.16(0.40)$ & $-0.38(0.39)$ & $0.09(0.40)$ & $-0.40(0.38)$ \\
\hline University degree & $-0.84(0.49)^{*}$ & $0.43(0.47)$ & $-0.92(0.48) *$ & $0.41(0.47)$ \\
\hline \multicolumn{5}{|l|}{ Interest in politics (ref. Very interested) } \\
\hline Not much & $-0.10(0.29)$ & $0.18(0.28)$ & $-0.06(0.29)$ & $0.17(0.28)$ \\
\hline Quite a lot & $-0.47(0.33)$ & $0.16(0.32)$ & $-0.41(0.33)$ & $0.14(0.32)$ \\
\hline Very much & $-0.90(0.46)^{*}$ & $0.40(0.45)$ & $-0.91(0.46)^{* *}$ & $0.40(0.45)$ \\
\hline \multicolumn{5}{|c|}{ Employment status (ref. Not employed) } \\
\hline Private company employee & $-0.11(0.30)$ & $0.17(0.28)$ & $-0.14(0.30)$ & $0.18(0.28)$ \\
\hline Public company employee & $0.08(0.34)$ & $0.18(0.32)$ & $0.04(0.34)$ & $0.20(0.32)$ \\
\hline Autonomous & $0.62(0.33) *$ & $-0.74(0.32) * *$ & $0.66(0.33) * *$ & $-0.72(0.31)^{* *}$ \\
\hline Atypical & $0.22(0.65)$ & $-1.18(0.62)^{*}$ & $0.20(0.64)$ & $-1.25(0.62)^{* * *}$ \\
\hline \multicolumn{5}{|l|}{ Geo-political zone (ref. North-west) } \\
\hline North-east & $-0.19(0.44)$ & $0.24(0.42)$ & $-0.08(0.43)$ & $0.36(0.42)$ \\
\hline 'Red belt' & $-0.52(0.42)$ & $0.43(0.41)$ & $-0.53(0.42)$ & $0.52(0.41)$ \\
\hline Center & $0.02(0.52)$ & $0.50(0.50)$ & $-0.01(0.51)$ & $0.52(0.50)$ \\
\hline South and islands & $0.12(0.33)$ & $0.46(0.31)$ & $0.11(0.32)$ & $0.46(0.31)$ \\
\hline Local strength of the coalition & $0.04(0.01)^{* * * *}$ & $0.05(0.01)^{* * *}$ & $0.06(0.02) * * *$ & $0.07(0.02)^{* * *}$ \\
\hline Relatives network's homogeneity & $0.05(0.00) * * *$ & $0.05(0.00)^{* * *}$ & $0.12(0.02) * * *$ & $0.08(0.02) * * *$ \\
\hline $\begin{array}{l}\text { Local strength } \times \text { relatives network's } \\
\text { homogeneity }(\times 100)\end{array}$ & & & $-0.13(0.04) * * *$ & $-0.07(0.03)^{* * *}$ \\
\hline Constant & $1.73(1.02)^{*}$ & $2.08(0.84)^{* *}$ & $0.67(1.06)$ & $1.13(0.95)$ \\
\hline $\operatorname{var}(\operatorname{lev} 2)$ & $0.65(0.19) * * *$ & $0.62(0.20)^{* * * *}$ & $0.61(0.34)^{* * *}$ & $0.62(0.20) * * *$ \\
\hline $\operatorname{var}(\operatorname{lev} 1)$ & $3.19(0.08) * * *$ & $3.01(0.08) * * *$ & $3.18(0.02) * * *$ & $3.00(0.08) * * *$ \\
\hline Observations & 970 & 945 & 970 & 945 \\
\hline Level-2 $n$ (municipalities) & 159 & 159 & 159 & 159 \\
\hline
\end{tabular}

$\mathrm{SE}$ in parentheses.

$\because * P<0.01, * * P<0.05, * P<0.1$.

homogeneity in the network/local context, there is an increase of PTV of 0.05 points. Thus, a difference of 50 percentage points leads to a 2.5 -point difference in PTV ( $25 \%$ of the scale range).

The second hypothesis states that there is some sort of tradeoff between the two contextual levels. In particular, if we accept the 'social bubble' argument, the effect of local context should be important only if the homogeneity of the familiar context is weak. Thus, it has been expected a negative interaction between the network's and local context's homogeneity. Models 3 and 4 show us that both the interactions for the Casa delle Libertà and the Unione present a negative and significant interaction. To make the result clearer, Figure 2 shows the marginal effects for the local contextual level of every coalition at different levels of network homogeneity. As it is possible to see in both the panels of the figure, the effect of local homogeneity (or strength) affects PTVs strongly only if the level of family homogeneity is weak. 

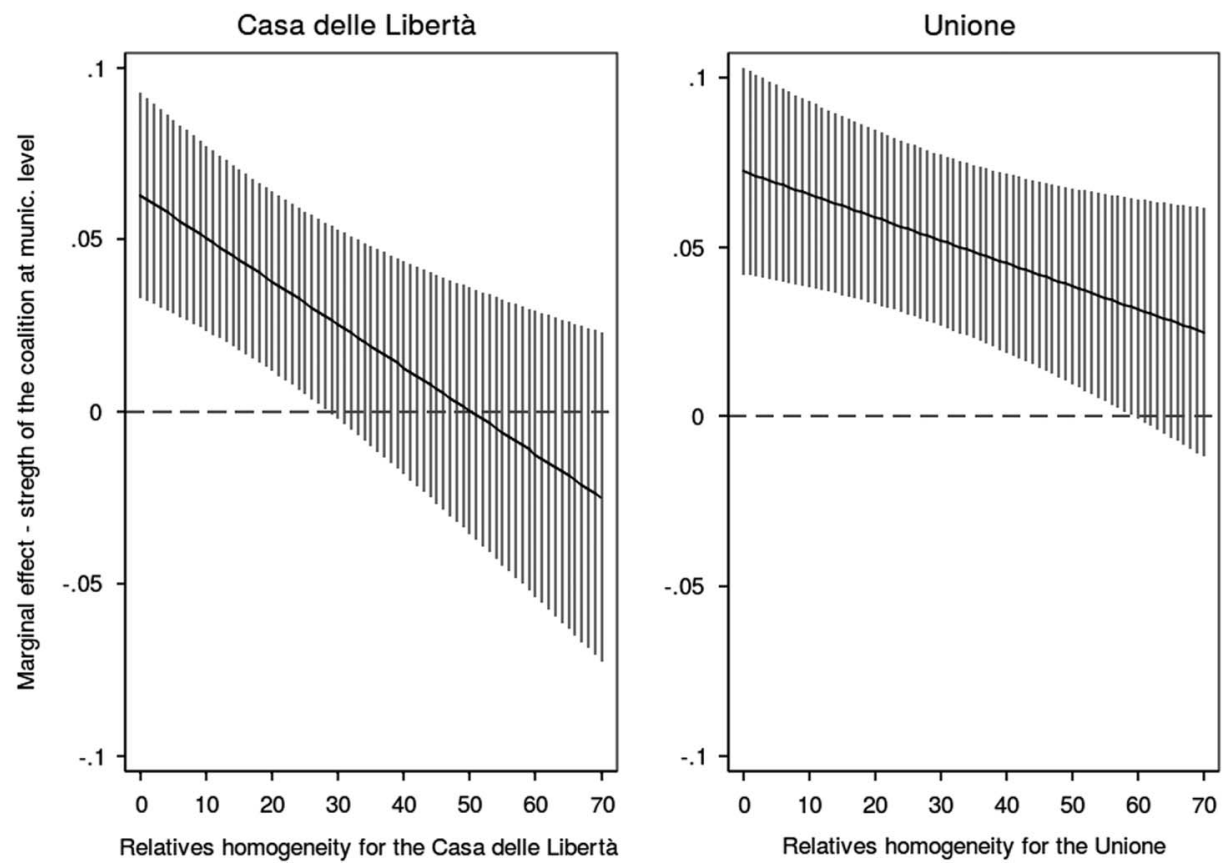

Figure 2 Marginal effects for municipal strength of coalitions at different levels of relatives network homogeneity - results for the Casa delle Libertà and the Unione.

As long as the family homogeneity is stronger, the effect of the local context becomes small, disappearing between $30 \%$ (for Casa delle Libertà's PTVs) and $55 \%$ (for the Unione's PTVs) relative homogeneity. ${ }^{7}$

\section{Conclusion and discussion}

This study aimed to test a set of hypotheses that connects contexts and individual political choices and attitudes. While the local contexts have been largely studied in European electoral studies (e.g. Pattie and Johnston, 2003), and represents one of the trademarks of Italian electoral studies (Galli, 1968; Shin and Agnew, 2002, 2008; Diamanti, 2003), less attention has been devoted to the effect that relatives, friends, acquaintances - in general, the interpersonal set of relations that people have in their everyday lives - have in shaping electoral behavior of individuals.

Even less consideration has been given to the interaction between these two contexts. The - actually quite condensed - literature on the topic has argued that circles (and especially those in which strong relations are the norm) can represent a 'social bubble' that to some extent contributes to isolate people from the effects of

\footnotetext{
${ }^{7}$ It is possible to see when the marginal effect is no longer significant by assessing when the confidence interval overlaps with the flat line that intercepts 0 .
} 
the broader geographical context (Huckfeldt and Sprague, 1987; Erisen and Erisen, 2012). In other words, if ego belongs to a highly homogeneous social circle (in this case, a familiar one), the prevalence of the party/coalition supported by the local context does not affect her as much as if she was in a non-homogeneous circle. We have hypothesized that the family, with high coercive power and strict ties among its members, constitutes an environment in which it is difficult to provide efficient social responses to avoid the pressure of relevant others. This hypothesis - together with a baseline hypothesis that assesses whether an effect of the two contexts, taken separately, exists - has been tested by means of 2006 National Elections data. The political structure of the competition in 2006 - characterized by a two-pole system with few non-aligned voters - has been judged to be optimal to test these hypotheses.

Results confirmed the two hypotheses, showing us a rapid drop of the significance and magnitude for the geographical context effect as long as the network becomes more homogeneous (and, it has been hypothesized, the pressure is stronger). We have also shown that the effect of the local context for the Unione remains strong also at high values of local homogeneity. In other words, if the effect of geographical context starts to be not significant when the network homogeneity of the Casa delle Libertà is $\sim 30 \%$, the effect of the context is still significant (and thus contributes to modify people's PTVs) at $50 \%$ of relatives' network homogeneity. This could be explained by the fact that, as mentioned above, the local structure of the center-left coalition is far more stable with respect to the center-right one. The local structure of center-left legacy has passed though weaker turmoil than the center-right one (see Shin and Agnew, 2002). Another reason could be the fact that the party that possesses the golden share of the coalition, Berlusconi's Forza Italia, has never had a clear and stable geographical structure at the geographical level. We must remember that a party with a strong rooting in a certain area does not mean only that people in that area have higher likelihoods to be affected by party supporters: rootedness of a party in a geographical place, for those who belong to that place, means also higher likelihoods to be exposed to associations and organizations tied to the party, or to be subjected to ideologically filled forms of secondary socialization. In other words, it is possible to imagine that places dominated by the center-right coalition present, to a lower degree, the complex set of organizational and pressure groups (politically tied to the dominant coalition) that are much more present in zones dominated by the center-left coalition (Shin and Agnew, 2002). That is a possible reason why we see that the effect of the geographical space is much more resilient in the centerleft case.

This work presents some problems that could affect our results. The first problem is related to the operationalization of the network. The concept of network is totally overlapped with that of relatives' network. In other words, friends, co-workers, and acquaintances circles are disregarded: this is because of a data-related problem that did not allow us to control for these other sources of pressure (although these variables have been collected, they are plagued by too many missing answers, see 
footnote 4). Although our theoretical focus has been on familiar network, the absence of the variables could have altered the magnitude and significance of our substantively crucial variable. However, attempts to introduce also other circles' homogeneity variables (not presented here) have been made, finding no clear evidence of changes in the pattern of the results. ${ }^{8}$

The second problem, more severe from a conceptual point of view, regards the nature of our results. So far, it has been argued that pressure of the contexts exerts an active role in shaping people's political view, but what if are people who choose to belong to more (or less) homogeneous circles and local context? In other words, our results are compatible both with influence-based and with selection/homophily interpretations (Fowler et al., 2011; Noel and Nyhan, 2011; Bello and Rolfe, 2014). As pointed out above, it is possible that people who have higher PTVs for a certain coalition would be more prone to choose politically agreeable discussants instead of what argued (i.e. that people are influenced by their discussants and, consequently, present higher PTVs for the coalition). It is possible to argue two objections that partly account for this alternative explanation. First, if we focus on the local context and the family as source of influence, we can argue that the individual is constrained in his/her choices. Local context and the family are, to some extent, that which the individual has not chosen. Referring only to the sole familiar circle, it is possible to partly avoid homophily issues. Second, it has been stressed above the role of interpersonal influence in shaping the structure of citizens' political preferences (see Klofstad, 2007), showing stronger effects for influence mechanisms compared with selection/homophily (Bello and Rolfe, 2014). In any case, we are aware of the fact that our results show only a descriptive figure of the flow of information among different contextual levels, arguing only theoretically on the underlying mechanisms that guide these empirical regularities. In other words, far from demonstrating in causal terms the theoretical framework exposed above, this article provides evidences that are compatible with such a figure. The only way in which it would be possible to overcome this issue is the employment of longitudinal cross-sectional data, which allows the measurement of political attitudes and network exposure in different phases in time, to tap mechanisms of interpersonal influence.

\section{Acknowledgment}

The author would also like to thank two anonymous reviewers for their helpful comments and advice.

\section{Funding}

The research received no grants from public, commercial, or non-profit funding agency.

\footnotetext{
${ }^{8}$ It has been decided not to include these results, considered the scarce number of cases and the instability of the estimates.
} 


\section{Data}

The replication dataset is available at http://thedata.harvard.edu/dvn/dv/ipsr-risp.

\section{References}

Agnew, J.A. (1987), Place and Politics: The Geographical Mediation of State and Society, Boston, MA and London: Allen and Unwin.

Agnew, J.A. (1996), 'Mapping politics: how context counts in electoral geography', Political Geography 15 (2): 129-146.

Baker, A., B. Ames and L.R. Renno (2006), 'Social context and campaign volatility in new democracies: networks and neighborhoods in Brazil's 2002 elections', American Journal of Political Science 50(2): 382-399.

Baldassarri, D. (2009), 'Social networks, political heterogeneity, and interpersonal influence. Evidence from the 2006 Italian elections'. Paper prepared for the Political Networks Workshop at the University of California, Davis.

Ballarino, G., H.M. Schadee and C. Vezzoni (2009), 'Classe sociale e voto in Italia, 1972-2006', Rivista Italiana di Scienza Politica 39(2): 263-294.

Barisione, M. (2001), 'Interesse per la politica, appartenenza di coalizione e giudizio sui leader: gli effetti della campagna elettorale', Rivista Italiana di Scienza Politica 31(3): 503-542.

Baybeck, B. and R. Huckfeldt (2002), 'Urban contexts, spatially dispersed networks, and the diffusion of political information', Political Geography 21(2): 195-220.

Bello, J. and M. Rolfe (2014), 'Is influence mightier than selection? Forging agreement in political discussion networks during a campaign', Social Networks 36(1): 134-146.

Berelson, B.R., P.F. Lazarsfeld and W.N. McPhee (1954), Voting: A Study of Opinion Formation in a Presidential Campaign, Chicago, IL: University of Chicago Press.

van der Brug, W., C. van der Eijk and M. Franklin (2007), The Economy and the Vote: Economic Conditions and Elections in Fifteen Countries, Cambridge: Cambridge University Press.

Campus, D., G. Pasquino and C. Vaccari (2008), 'Social networks, political discussion and voting in Italy: a study of the 2006 election', Political Communication 25(4): 423-444.

De Sio, L. (ed.) (2011), La Politica Cambia, i Valori Restano? Una Ricerca Sulla Cultura Politica dei Cittadini Toscani, Firenze: Firenze University Press.

Diamanti, I. (1993), La Lega. Geografia, Storia e Sociologia di un Nuovo Soggetto Politico, Roma: Donzelli.

Diamanti, I. (2003), Bianco, Rosso, Verde... e Azzurro: Mappe e Colori dell'Italia Politica, Bologna: Il Mulino.

van der Eijk, C. and M. Franklin (1996), Choosing Europe? The European Electorate and National Politics in the Face of Union, Ann Arbor, MI: University of Michigan Press.

van der Eijk, C., W. van der Brug, M. Kroh and M. Franklin (2006), 'Rethinking the dependent variable in voting behavior: on the measurement and analysis of electoral utilities', Electoral Studies 25(3): 424-447.

Erisen, E. and C. Erisen (2012), 'The effect of social networks on the quality of political thinking', Political Psychology 33(6): 839-865.

Eveland, W.P., H. Song and P.A. Beck (2015), 'Cultural Variations in the Relationships Among Network Political Agreement, Political Discussion Frequency, and Voting Turnout', International Journal of Public Opinion Research, online first article (code: edv007).

Fowler, J.H., M.T. Heaney, D.W. Nickerson, J.F. Padgett and B. Sinclair (2011), 'Causality in political networks', American Politics Research 39(2): 437-480.

Galli, G. (ed.) (1968), Il Comportamento Elettorale in Italia: un'indagine Ecologica sulle Elezioni in Italia tra il 1946 e il 1963, Bologna: Il Mulino.

Gelman, A. and H. Hill (2006), Data Analysis Using Regression and Multilevel/Hierarchical Models, New York: Cambridge University Press.

Granovetter, M.S. (1973), 'The strength of weak ties', American Journal of Sociology 78(6): 1360-1380. 
Granovetter, M.S. (1983), 'The strength of weak ties: a network theory revisited', Sociological Theory 1(1): 201-233.

Guidetti, M., N. Cavazza and A.R. Graziani (2016), 'Perceived disagreement and heterogeneity in social networks: distinct effects on political participation', The Journal of Social Psychology 156(2): 222-242.

Hopmann, D.N. (2012), 'The consequences of political disagreement in interpersonal communication: new insights from a comparative perspective', European Journal of Political Research 51(2): $265-287$.

Huckfeldt, R. (1986), Politics in Context: Assimilation and Conflict in Urban Neighborhoods, Baltimore, MD: Algora Publishing.

Huckfeldt, R. and J.D. Sprague (1987), 'Networks in context: the social flow of political information', The American Political Science Review 81(4): 1197-1216.

Huckfeldt, R. and J.D. Sprague (1995), Citizens, Politics and Social Communication: Information and Influence in an Election Campaign, New York: Cambridge University Press.

Huckfeldt, R., J. Sprague and J. Levine (2000), 'The dynamics of collective deliberation in the 1996 election: campaign effects on accessibility, certainty, and accuracy', American Political Science Review 94 : 641-651.

Huckfeldt, R., P.E. Johnson and J.D. Sprague (2004), Political Disagreement: The Survival of Diverse Opinions Within Communication Networks, New York: Cambridge University Press.

Huckfeldt, R., P.A. Beck, R.J. Dalton and J. Levine (1995), 'Political environments, cohesive social groups, and the communication of public opinion', American Journal of Political Science 39(4): 1025-1054.

Italian National Election Studies (ITANES) (ed.) (2006), Dov'è la Vittoria?: il voto del 2006 Raccontato dagli Italiani, Bologna: Il Mulino.

Klofstad, C.A. (2007), 'Talk leads to recruitment: how discussions about politics and current events increase civic participation', Political Research Quarterly 60(2): 180-191.

Klofstad, C.A., S.D. McClurg and M. Rolfe (2009), 'Measurement of political discussion networks: a comparison of two "name generator" procedures', Public Opinion Quarterly 73(3): 462-483.

Latané, B. (1996), 'Dynamic social impact: the creation of culture by communication', Journal of Communication 46(4): 13-25.

Lomi, A., T.A.B. Snijders, C.E.G. Steglich and V.J. Torló (2011), 'Why are some more peer than others? Evidence from a longitudinal study of social networks and individual academic performance', Social Science Research 40(6): 1506-1520.

Marsh, M. (2002), 'Electoral context', Electoral Studies 21(2): 207-217.

Mollenhorst, G., B. Volker and H. Flap (2008), 'Social contexts and core discussion networks', Social Forces 86: 937-965.

Mutz, D.C. (2002), 'The consequences of cross-cutting networks for political participation', American Journal of Political Science 46(4): 838-855.

Newell, J.L. (2006), 'The Italian election of May 2006: myths and realities', West European Politics 29(4): 802-813.

Noel, H. and B. Nyhan (2011), 'The "unfriending” problem: the consequences of homophily in friendship retention for causal estimates of social influence', Social Networks 33(3): 211-218.

Pattie, C.J. and R.J. Johnston (2003), 'Local battles in a national landslide: constituency campaigning at the 2001 British General Election', Political Geography 22(4): 381-414.

Rolfe, M. (2009), 'Conditional choice processes', in P. Bearman and P. Hedström (eds), Oxford Handbook of Analytical Sociology, Oxford: Oxford University Press, pp. 419-436.

Sani, G. (1976), 'Political traditions as contextual variables: partisanship in Italy', American Journal of Political Science 20(3): 375-405.

Shin, M.E. and J.A. Agnew (2002), 'The geography of party replacement in Italy, 1987-1996', Political Geography 21(2): 221-242.

Shin, M.E. and J.A. Agnew (2008), Berlusconi's Italy: Mapping Contemporary Italian Politics, Philadelphia, PA: Temple University Press. 
Snijders, T.A.B. and R.J. Bosker (1999), Multilevel Analysis: An Introduction to Basic and Advanced Multilevel Modeling, Los Angeles, CA: Sage.

Tillie, J.N. (1995), Party Utility and Voting Behaviour, Amsterdam: Het Spinhuis.

Trigilia, C. (1981), Le Subculture Politiche Territoriali, Quaderno n. 16, Milano: Fondazione Giangiacomo Feltrinelli.

Vezzoni, C. (2008), 'Contesto territoriale e voto nelle elezioni del 2006. Un approccio multilivello', Polis 22(1): 193-220.

Vezzoni, C. and M. Mancosu (2016), 'Diffusion processes and discussion networks: an analysis of the propensity to vote for the 5 Star Movement in the 2013 Italian election', Journal of Elections, Public Opinion \& Parties 26(1): 1-21.

Zuckerman, A.S. (ed.) (2005), The Social Logic of Politics: Personal Networks as Contexts for Political Behavior, Philadelphia, PA: Temple University Press.

Zuckerman, A.S., J. Dasovic and J. Fitzgerald (2007), Partisan Families: The Social Logic of Bounded Partisanship in Germany and Britain, New York: Cambridge University Press.

\section{Appendix 1}

Table A1. Descriptive statistics for the variables of models $1-4-$ Table $1(n=970)$

\begin{tabular}{|c|c|c|c|c|}
\hline Variables & Mean & Std. dev. & 10th percentile & 90th percentile \\
\hline \multicolumn{5}{|l|}{ Main predictors } \\
\hline PTV Casa delle Libertà & 4.95 & 3.57 & 1 & 10 \\
\hline PTV Unione & 5.80 & 3.59 & 1 & 11 \\
\hline Local strength Casa delle Libertà & 48.53 & 10.24 & 36.23 & 61.43 \\
\hline Relatives network's homogeneity - Casa delle Libertà & 19.54 & 27.08 & 0.00 & 67.50 \\
\hline Local Strength Unione & 47.70 & 10.12 & 34.76 & 61.67 \\
\hline Relatives network's homogeneity - Unione & 26.85 & 31.48 & 0.00 & 81.00 \\
\hline \multicolumn{5}{|l|}{ Control variables } \\
\hline Age & 47.11 & 16.53 & 25 & 70 \\
\hline Elementary school & 0.19 & 0.39 & 0 & 1 \\
\hline Middle school & 0.35 & 0.48 & 0 & 1 \\
\hline High school & 0.37 & 0.48 & 0 & 1 \\
\hline University degree & 0.10 & 0.30 & 0 & 0 \\
\hline Very interested & 0.28 & 0.45 & 0 & 1 \\
\hline Not much & 0.41 & 0.49 & 0 & 1 \\
\hline Quite a lot & 0.26 & 0.44 & 0 & 1 \\
\hline Very much & 0.06 & 0.23 & 0 & 0 \\
\hline Not employed & 0.49 & 0.50 & 0 & 1 \\
\hline Private company employee & 0.23 & 0.42 & 0 & 1 \\
\hline Public company employee & 0.12 & 0.33 & 0 & 1 \\
\hline Autonomous & 0.13 & 0.34 & 0 & 1 \\
\hline Atypical & 0.02 & 0.15 & 0 & 0 \\
\hline North-west & 0.25 & 0.44 & 0 & 1 \\
\hline North-east & 0.12 & 0.32 & 0 & 1 \\
\hline 'Red belt' & 0.16 & 0.37 & 0 & 1 \\
\hline Center & 0.09 & 0.29 & 0 & 0 \\
\hline South and islands & 0.38 & 0.48 & 0 & 1 \\
\hline
\end{tabular}

PTV $=$ propensity to vote. 